\title{
OPTIMALISASI BIAYA DAN WAKTU TERHADAP PERENCANAAN JALAN DENGAN MENGGUNAKAN METODE BINA MARGA 1987 DENGAN BERBAGAI TEBAL INDEK PERKERASAN (Studi Kasus: Pada Ruas Jalan Puruk Cahu - Km 50 - Batas Kota Muara Teweh Kabupaten Barito Utara)
}

\author{
COSTS AND TIME OPTIMIZATION OF ROAD PLANNING USING THE BINA MARGA 1987 \\ METHOD WITH VARIOUS THICKNESS OF PAVEMENT INDEX (Case Study: On Puruk Cahu - Km \\ 50 - Muara Teweh City Boundary, North Barito Regency)
}

\section{Erlin Meyer}

Aparatur Sipil Negara

Balai Pelaksanaan Jalan Nasional Palangka Raya

Direktorat Jenderal Bina Marga Kementerian Pekerjaan Umum dan Perumahan Rakyat

Korespondensi: erlinmeyer1974@gmail.com

\begin{abstract}
ABSTRAK
Perencanaan perkerasan yang baik, karena dengan begitu konstruksi perkerasan jalan mampu memikul beban kendaraan yang melintas di atasnya dan menyebarkan beban tersebut kelapisan-lapisan di bawahnya, termasuk tanah dasar tersebut, tanpa menimbulkan kerusakan yang berarti pada konstruksi jalan itu sendiri. Tujuan penelitian ini adalah untuk mendapatkan alternatif indek tebal perkerasan jalan yang paling efisien dan mendapatkan biaya dan waktu yang diperlukan. Hasil penelitian menunjukkan bahwa Indeks Tebal Perkerasan (ITP) dengan menggunakan Metode Bina Marga = 7,48 dan Metode AASHTO $1993=10,20$ mempunyai selisih 2,72. Perbedaan Indeks Tebal Perkerasan (ITP) tersebut mengakibatkan penambahan tebal perkerasan dengan menggunakan Metode AASHTO 1993. Indeks Tebal Perkerasan (ITP) yang ekonomis adalah ITP Metode Bina Marga dengan biaya pembangunan Rp. 12,7 Milyar, dengan penghematan Rp. 3,8 Milyar. Dengan menetapkan tebal perkerasan pada lapis pondasi atas $=20 \mathrm{~cm}$ yang sama didapat bahwa jenis bahan Aggregat Kls. B, CBR 80\% lebih murah di banding semen + CTRB dengan penghematan Rp.913.991.544,1 milyar. Waktu yang diperlukan dalam pelaksanaan Metode Bina Marga lebih efisien dibandingkan dengan Metode AASHTO 1993 dengan penghematan 44 hari, hal ini disebabkan Pekerjaan semen + CTRB = $15+29$ = 44 hari. Sedangkan Aggregat Kls. B, CBR 80\% hanya memerlukan 22 hari, sehingga menghemat 22 juga disebabkan ITP Metode AASHTO 1993 lebih besar sehingga memerlukan penambahan tebal lapis pondasi bawah Aggregat Kls. C, CBR 30\% sebesar $22 \mathrm{~cm}$ dengan demikian menambah durasi waktu pelaksanaan sebesar 24 hari
\end{abstract}

Kata Kunci: Biaya, indeks tebal perkerasan, waktu pelaksanaan perkerasan jalan

\section{ABSTRACT}

Pavement planning is good, because in this way the pavement construction is able to carry the load of vehicles passing on it and spread the load to the layers beneath it, including the subgrade, without causing significant damage to the road construction itself. The purpose of this study is to obtain the most efficient alternative pavement thickness index and to obtain the required cost and time. The results showed that the Pavement Thickness Index (ITP) using the Bina Marga Method = 7.48 and the 1993 AASHTO Method $=10.20$ had a 
difference of 2.72. The difference in Pavement Thickness Index (ITP) resulted in the addition of pavement thickness using the 1993 AASHTO Method. The economical Pavement Thickness Index (ITP) was the ITP Bina Marga Method with a construction cost of Rp. 12.7 billion, with savings of Rp. 3.8 billion. By determining the pavement thickness at the same base layer $=20 \mathrm{~cm}$, it is found that the type of material is Aggregate Kls. B, CBR is $80 \%$ cheaper than cement + CTRB with savings of Rp. 913,991,544, $\sim 1$ billion. The time required in implementing the Bina Marga Method is more efficient than the 1993 AASHTO Method with a savings of 44 days, this is due to cement work $+C T R B=15+29=44$ days. While Aggregate Kls. B, CBR $80 \%$ only takes 22 days, thus saving 22 is also due to the larger ITP of the 1993 AASHTO Method so that it requires additional thickness of the base layer under Aggregate Kls. C, CBR 30\% of $22 \mathrm{~cm}$ thus increasing the duration of the implementation time by 24 days

Keywords: Cost, pavement thickness index, time of pavement implementation.

\section{PENDAHULUAN}

\section{Latar Belakang}

Perencanaan perkerasan Jalan yang baik (ekonomis dan efisien) yang mampu memikul beban kendaraan yang melintas di atasnya dan menyebarkan beban tersebut kelapisan-lapisan di bawahnya, termasuk tanah dasar tersebut, tanpa menimbulkan kerusakan yang berarti pada konstruksi jalan itu sendiri.

\section{Rumusan Masalah}

Dari latar belakang tersebut dapat dibuat rumusan masalah sebagai berikut:

1. Bagaimana alternatif yang bisa digunakan pada indek tebal perkerasan jalan.

2. Berapa indek tebal perkerasan jalan yang paling efisien.

3. Berapa biaya dan waktu yang diperlukan untuk pelaksanaan jalan.

\section{Tujuan Penelitian}

Tujuan dari penelitian adalah :

1. Mendapatkan alternatif indek tebal perkerasan yang bisa digunakan pada jalan

2. Mendapatkan indek tebal perkerasan jalan yang paling efisien

3. Mendapatkan biaya dan waktu yang diperlukan untuk pelaksanaan jalan

\section{Manfaat Penelitian}

Manfaat yang diperoleh dari Jalan ruas Puruk Cahu - Km. 50 (Pasar Punjung) - Batas Kota Muara Teweh adalah sebagai berikut:
1. Sebagai masukan bagi Pemerintah Kabupaten Barito Utara pada Umumnya dan PU Bina Marga Kabupaten Barito Utara

2. Sebagai referensi untuk perencanaan Pembangunan atau jalan lain di Wilayah Kabupaten Barito Utara

3. Bagi Peneliti, penelitian ini bermanfaat untuk menambah wawasan dan sarana aplikasi teori yang diterima selama menempuh kuliah dengan data empiris yang ada dilapangan serta pengalaman penelitian khususnya tentang perencanaan dan teknis pelaksanaan perkerasan jalan dengan metode analisa komponen.

\section{Batasan dan Ruang Lingkup Penelitian}

Batasan dan ruang lingkup penelitian ini adalah sebagai berikut:

a. Penelitian dilakukan hanya pada perencanaan dan perhitungan tebal perkerasan dan biaya dengan metode analisa komponen

b. Tidak merencanakan desain bangunan pelengkap (jembatan, gorong-gorong)

c. Tidak membahas derajat kejenuhan jalan

\section{TINJAUAN PUSTAKA}

\section{Penelitian Terdahulu}

Femy Arizona dan Agus Taufik Mulyono (2015) dengan judul Biaya Penanganan Jalan Nasional Berdasarkan Kondisi Kerusakan Jalan dan Modulus Efektif Perkerasan Pada Ruas Jalan Nasional di Demak

Irwan Lie Keng Wong (2013), dengan judul Studi Perbandingan Perkerasan Jalan Lentur Metode Bina Marga Dan AASTHO Dengan 
Menggunakan Uji Dynamic Cone Penetration (Ruas Jalan Bungku - Funuasingko Kabupaten Morowali)

\section{Perkerasan Jalan}

Perkerasan jalan merupakan lapisan perkerasan yang terletak di antara lapisan tanah dasar dan roda kendaraan, yang berfungsi memberikan pelayanan kepada sarana transportasi, dan selama masa pelayanannya diharapkan tidak terjadi kerusakan yang berarti.

\section{Perkerasan Lentur (Flexible Pavement)}

Sesuai undang-undang tentang jalan No.38 tahun 2004 dan Peraturan Pemerintah No.34 tahun 2006, sistem jaringan jalan di Indonesia dapat dibedakan atas sistem jaringan jalan primer dan sistem jaringan jalan sekunder.

\section{Lalu Lintas Harian Rata-rata}

Jumlah kendaran yang hendak memakai jalan dinyatakan dalam volume lalu lintas. Untuk kebutuhan perencanaan tebal perkerasan dapat diperoleh data-data sebagai berikut:

a. Lalu lintas harian rata-rata setiap jenis kendaraan didapat dengan mengadakan pengamatan pada awal umur rencana, dihitung untuk dua arah pada jalan tanpa median atau masing-masing arah pada jalan dengan median.

b. Lintas Ekuivalen Permulaan (LEP), yang dihitung dengan rumus:

$$
\mathrm{LEP}=\Sigma \mathrm{LHRj} \times \mathrm{Cj} \times \mathrm{Ej}
$$

c. Lintas Ekuivalen Akhir (LEA), yang dihitung dengan rumus:

$$
\mathrm{LEA}=\Sigma \operatorname{LHRj}(1+\mathrm{i}) \mathrm{UR} \times \mathrm{Cj} \times \mathrm{Ej}
$$

d. Lintas Ekuivalen Tengah, yang dihitung dengan rumus:

$$
\text { LET }=\frac{\text { LEP }+ \text { LEA }}{2}
$$

e. Lintas Ekuivalen Rencana, dihitung dengan rumus:

$$
\text { LER = LET } x \text { FP }
$$

\section{Angka Ekivalen Beban Sumbu}

Jenis kendaraan yang memakai jalan beraneka ragam, bervariasi baik ukuran, berat total, konfigurasi dan beban sumbu, daya. Oleh karena itu volume lalu lintas umumnya dikelompokkan atas beberapa kelompok yang masing-masing kelompok diwakili oleh satu jenis kendaraaan.
Angka ekuivalen masing-masing golongan beban sumbu untuk setiap ken-daraan ditentukan dengan rumus:

a. Untuk sumbu tunggal

$$
\mathrm{E}=\left[\frac{\mathrm{P}(\mathrm{kg})}{8.160}\right]^{4}
$$

b. Untuk sumbu ganda

$$
\mathrm{E}=0,086 x\left[\frac{\mathrm{P}(\mathrm{kg})}{8.160}\right]^{4}
$$

c. Untuk sumbu tripel

$$
\mathrm{E}=0,053 x\left[\frac{\mathrm{P}(\mathrm{kg})}{8.160}\right]^{4}
$$

\section{Daya Dukung Tanah}

Daya Dukung Tanah Dasar (DDT) dan California Bearing Ratio (CBR) merupakan perbandingan beban penetrasi pada suatu bahan dengan beban standar pada penetrasi dan kecepatan pembebanan yang sama. Berdasarkan cara mendapatkan contoh tanahnya, CBR dapat dibagi atas:

a. CBR lapangan, disebut juga $\mathrm{CBR}_{\text {inplace }}$ atau field CBR.

Gunanya untuk mendapatkan nilai CBR asli di lapangan sesuai dengan kondisi tanah saat itu dimana tanah dasarnya sudah tidak akan dipadatkan lagi. Pemeriksaan dilakukan saat kadar air tanah tinggi atau dalam kondisi terburuk yang mungkin terjadi.

b. CBR lapangan rendaman / Undisturb saoked CBR

Gunanya untuk mendapatkan besarnya nilai CBR asli di lapngan pada keadaan jenuh air, dan tanah mengalami pengembangan maksimum. Pemeriksanaan dilaksanakan pada kondisi tanah dasar tidak dalam keadaan jenuh air. Hal ini sering digunakan untuk menentukan daya dukung tanah di daerah yang lapisan tanah dasarnya sudah tidak akan dipadatkan lagi, terletak di daerah yang badan jalanya sering terendam air pada musim hujan dan kering pada musim kemarau. sedangkan pemeriksaan dilakukan di musim kemarau.

c. CBR rencana titik / CBR laboratorium / desain CBR

Tanah dasar (subgrade) pada konstruksi jalan baru merupakan tanah asli, tanah timbunan, 
atau tanah galian yang sudah dipadatakan sampai kepadatan 95\% kepadatan maksimum. Dengan demikian daya dukung tanah dasar tersebut merupakan nilai kemampuan lapisan tanah memikul beban setelah tanah tersebut di padatkan.

Data CBR yang digunakan adalah harga-harga CBR dari pemeriksaan lapangan dan uji laboratorium dari data CBR ditentukan nilai CBR terendah, kemudian ditentukan harga CBR yang mewakili atau CBR segmen. Dalam menentukan CBR segmen terdapat 2 cara yaitu:

Secara analitis

$\mathrm{CBR}_{\text {segmen }}=\mathrm{CBR}_{\text {rata-rata }}-\left(\mathrm{CBR}_{\text {maks }}-\mathrm{CBR}_{\text {min }}\right) / \mathrm{R}$

Dimana harga $\mathrm{R}$ tergantung dari jumlah data yang terdapat dalam satu segmen.

Tabel 1. Nilai R Untuk Perhitungan CBR Segmen

\begin{tabular}{cc}
\hline $\begin{array}{c}\text { Jumlah Titik } \\
\text { Pengamatan }\end{array}$ & Nilai R \\
\hline 2 & 1,41 \\
3 & 1,91 \\
4 & 2,24 \\
5 & 2,48 \\
6 & 2,67 \\
7 & 2,83 \\
8 & 2,96 \\
9 & 3,08 \\
$>10$ & 3,18 \\
\hline
\end{tabular}

Sumber : SKBI - 2.3.26.1987

Secara Grafis Tentukan data CBR yang sama dan lebih besar dari masing-masing nilai pada data CBR. Angka dengan jumlah terbanyak dinyatakan dalam angka $100 \%$, sedangkan jumlah lainnya merupakan prosentase dari angka $100 \%$ tersebut. dari agka-angka tersebut dibuat grafik hubungan antara harga CBR dan angka prosentasenya. Ditarik garis dari angka prosentase $90 \%$ menuju grafik untuk memperoleh nilai CBR segmen.

Dari nilai CBR segmen yang telah ditentukan dapat diperoleh nilai DDT dari grafik kolerasi DDT dan CBR, dimana grafik DDT dalam skala linier, dan grafik CBR dalam skala logaritma. Hubungan tersebut digambarkan pada Gambar sebagai berikut:

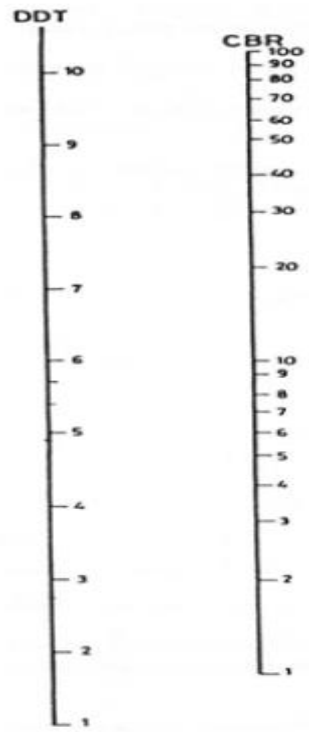

Gambar 1. Korelasi antara DDT dan CBR Sumber : SKBI - 2.3.26.1987

Selain menggunakan grafik tersebut, nilai DDT dari suatu Harga CBR juga dapat ditentukan menggunakan rumus:

$$
\mathrm{DDT}=1,6649+4,3592 \log (\mathrm{CBR})
$$

\section{Umur Rencana}

Umur rencana adalah waktu dalam tahun dihitung mulai dibukanya jalan sampai saat diperlukannya perbaiakan berat atau telah dianggap perlu memberi lapisan permukaan baru.

\section{Faktor Regional}

Faktor Regional adalah keadaan lapangan yang mencakup permeabilitas tanah, perlengkapan drainase, bentuk alinyemen, prosentase kendaraan berat dengan MST $\geq 13$ ton dan kendaraan yang berhenti, serta iklim.

\section{Indeks Permukaan}

Indeks Permukaan menyatakan nilai ketidakrataan dan kekuatan perkerasan yang berhubungan dengan tingkat pelayanan bagi lalu lintas yang lewat.

\section{Koefisien Kekuatan Relatif (a)}

Pedoman ini memperkenalkan kolerasi antara koefisien kekuatan relatif dengan nilai mekanistik, yaitu modulus resilien.

\section{Lalu Lintas Pada Lajur Rencana}

Lalu lintas lajur rencana $\left(\mathrm{W}_{18}\right)$ diberikan dalam kumulatif beban gandar standar. Untuk 
mendapatkan lalu lintas pada lajur rencana ini digunakan perumusan sebagai berikut ini:

$$
\mathrm{W}_{18}=\mathrm{D}_{\mathrm{D}} \times \mathrm{D}_{\mathrm{L}} \times \hat{\mathrm{W}}_{18}
$$

Lalu-lintas yang digunakan untuk perencanaan tebal perkerasan lentur dalam pedoman ini adalah lalu-lintas kumulatif pada lajur rencana selama setahun (w18) dengan besaran kenaikan lalu lintas (traffic growth). Secara numerik rumusan lalu-lintas kumulatif ini adalah sebagai berikut:

$$
\mathrm{W}_{\mathrm{t}}=\mathrm{w}_{18} \times \frac{(1+\mathrm{g})^{\mathrm{n}}-1}{\mathrm{~g}}
$$

Metode yang digunakan adalah Metode $\mathrm{Pt}$ T-01-2002-B, yang diadopsi dari Metode ASHTO
1993 dengan langkah-langkah perencanaan sebagai berikut:

a. Menentukan Indeks Permukaan awal $\left(\mathrm{IP}_{0}\right)$

Indeks permukaan menyatakan nilai dari kehalusan serta kekokohan permukaan yang bertalian dengan tingkat pelayanan bagi lalu lintas yang lewat. Nilai indeks permukaan awal (IPo) ditentukan dari jenis lapis permukaan.

b. Menentukan Indeks Permukaan akhir $\left(\mathrm{IP}_{\mathrm{t}}\right)$

Metode Pt T-01-2002-B yang mempunyai lebih banyak pilihan nilai dibandingkan dengan Metode AASHTO 1993. Nilai indeks permukaan akhir (IPt) ditentukan dari nilai LER.

c. Menentukan tebal minimum masing- masing perkerasan

Tabel 2. Tebal Minimum Lapis Permukaan

\begin{tabular}{ccl}
\hline ITP & Tebal Minimum $(\mathrm{cm})$ & \multicolumn{1}{c}{ Bahan } \\
\hline$<3,00$ & 5 & Lapis pelindung (Buras/Burtu/Burda ) \\
$3,00-6,70$ & 5 & Laston / Aspal Macadam / HRA /Lasbutag / Laston \\
$6,71-7,49$ & 7,5 & Lapen / Aspal Macadam / HRA / Lasbutag / Laston \\
$7,50-9,99$ & 7,5 & Lasbutag / laston \\
$>10,00$ & 10 & Laston \\
\hline
\end{tabular}

Sumber : SKBI - 2.3.23.1987

\begin{tabular}{|c|c|c|}
\hline ITP & $\begin{array}{l}\text { Tebal Minimum } \\
(\mathrm{cm})\end{array}$ & Bahan \\
\hline$<3,00$ & 15 & $\begin{array}{l}\text { Batu pecah, stabilisasi tanah dengan semen, stabilisasi tanah dengan } \\
\text { kapur }\end{array}$ \\
\hline $3,00-7,49$ & 20 & $\begin{array}{l}\text { Batu pecah, stabilisasi tanah dengan semen, stabilisasi tanah dengan } \\
\text { kapur }\end{array}$ \\
\hline $7,50-9,99$ & 20 & $\begin{array}{l}\text { Batu pecah, stabilisasi tanah dengan semen, stabilisasi tanah dengan } \\
\text { kapur, pondasi macadam }\end{array}$ \\
\hline $10,00-12,14$ & 20 & $\begin{array}{l}\text { Batu pecah, stabilisasi tanah dengan semen, stabilisasi tanah dengan } \\
\text { kapur, pondasi macadam, lapen, laston atas }\end{array}$ \\
\hline$>12,25$ & 25 & $\begin{array}{l}\text { Batu pecah, stabilisasi tanah dengan semen, stabilisasi tanah dengan } \\
\text { kapur, pondasi macadam, lapen, laston atas }\end{array}$ \\
\hline
\end{tabular}

Tabel 3. Batas Minimum Tebal Lapis Pondasi

Sumber : SKBI - 2.3.23.1987

\section{d. Reliabilitas}

Konsep Reliabilitas merupakan upaya untuk menyertakan derajat kepastian kedalam proses perencanaan untuk menjamin bermacammacam alternatif perencanaan akan bertahan selama selang waktu yang direncanakan (umur rencana).

\section{e. Modulus Resilien}

Dalam pedoman ini diperkenalkan modulus resilien (MR) sebagai parameter tanah dasar yang digunakan dalam perencanaan.
Modulus resilien (MR) tanah dasar juga dapat diperkirakan dari CBR standar dan hasil atau nilai tes soil index. Korelasi Modulus Resilien dengan nilai CBR berikut ini dapat digunakan untuk tanah berbutir halus (fine-grained soil) dengan nilai CBR terendah 10 atau lebih kecil.

$$
\mathrm{MR}(\mathrm{psi})=1.500 \times \mathrm{CBR}
$$

f. Batas-batas Minimum Tebal Lapisan
Perkerasan


Pada saat menentukan tebal lapis perkerasan, perlu dipertimbangkan keefektiannya dari segi biaya, pelaksanaan konstruksi, dan batasan pemeliharaan untuk menghindari kemungkinan dihasilkannya perencanaan yang tidak praktis. Dari segi keefektifan biaya, jika perbandingan antara biaya untuk untuk lapisan pertama dan lapisan kedua lebih kecil dari pada perbandingan tersebut dikalikan dengan koefisien drainase, maka perencanaan yang secara ekonomis optimum adalah apabila digunakan tebal lapis pondasi minimum.

Dari parameter-parameter tersebut kemudian diperoleh nilai ITP dan nilai koefisien kekuatan relatif untuk masing-masing bahan perkerasan. Tebal masing-masing bahan perkerasan untuk masing-masing lapis permukaan, lapis pondasi, dan lapis pondasi bawah dapat dihitung dengan rumus :

$$
\text { ITP }=a_{1} \cdot D_{1}+a_{2} \cdot D_{2}+a_{3} \cdot D_{3}
$$

a. Perencanaan Tebal Perkerasan Lentur Metoda Bina Marga 1989

Perencanaan tebal lapisan perkerasan lentur jalan raya Metode Bina Marga 1989 merupakan metode yang didasarkan pada Bina Marga 1987 yaitu Petunjuk Perencanaan Tebal Perkerasan Lentur Jalan Raya dengan Metode Analisa Komponen, Rumus dasar yang digunakan pada rumus (14)

b. Perencanaan Tebal Perkerasan Lentur Metoda AASTHO

Selain menggunakan nomogram, ITP juga dapat dihitung dengan menggunakan rumus (15) berikut ini (Departemen Permukiman \& Prasarana Wilayah Pt T-01-2002-B, 2002)

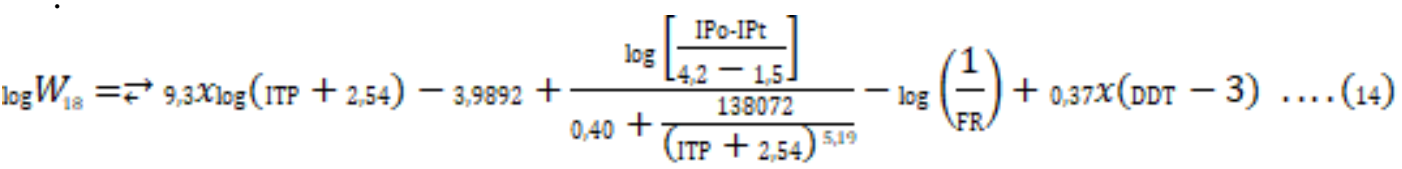

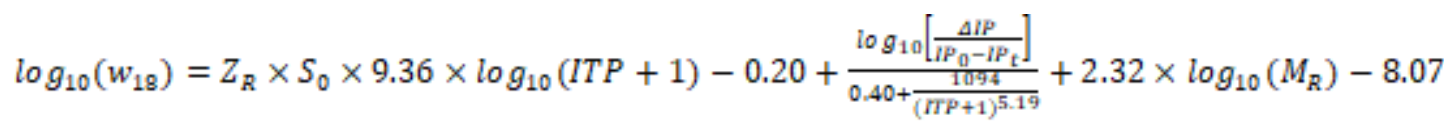

\section{CTRB (Cement Treated Recycling Base)}

Fungsi lapis pondasi antara lain adalah sebagai perletakan atau lantai kerja terhadap lapis permukaan dan lapisan perkerasan yang menahan gaya lintang dari beban roda dan menyebarkan beban ke lapisan di bawahnya.

\section{Rencana Anggaran Biaya Proyek}

Salah satu tahap penting dalam rangka pelaksanaan suatu kontruksi adalah perhitungan atau perkiraan biaya yang diperlukan untuk pembangunannya.

\section{METODE PENELITIAN}

\section{Rancangan Penelitian}

Rancangan penelitian dalam penelitian ini seperti pada Gambar 2.

\section{Subyek Penelitian}

\section{Populasi}

Populasi penelitian ini adalah proyek di lingkungan Dinas PU Bina Marga di Kabupaten Barito Utara pada Tahun Anggaran 2015.

\section{Sampel}

Sampel penelitian ini adalah kegiatan proyek Peningkatan Struktur Jalan Batas Kota Muara Teweh - Benangin, Kabupaten Barito Utara.

\section{Lokasi dan Waktu Penelitian}

Lokasi penelitian adalah Peningkatan Struktur Jalan Puruk Cahu - Batas Kota Muara Teweh, lama waktu penelitian kurang lebih 2 bulan.

\section{Instrumen Penelitian}

Data yang diperlukan untuk penelitian ini adalah data lalu lintas dan pertumbuhan lalu lintas, CBR, kelandaian Jalan, curah hujan, gambar lokasi proyek, gambar potongan melintang jalan 


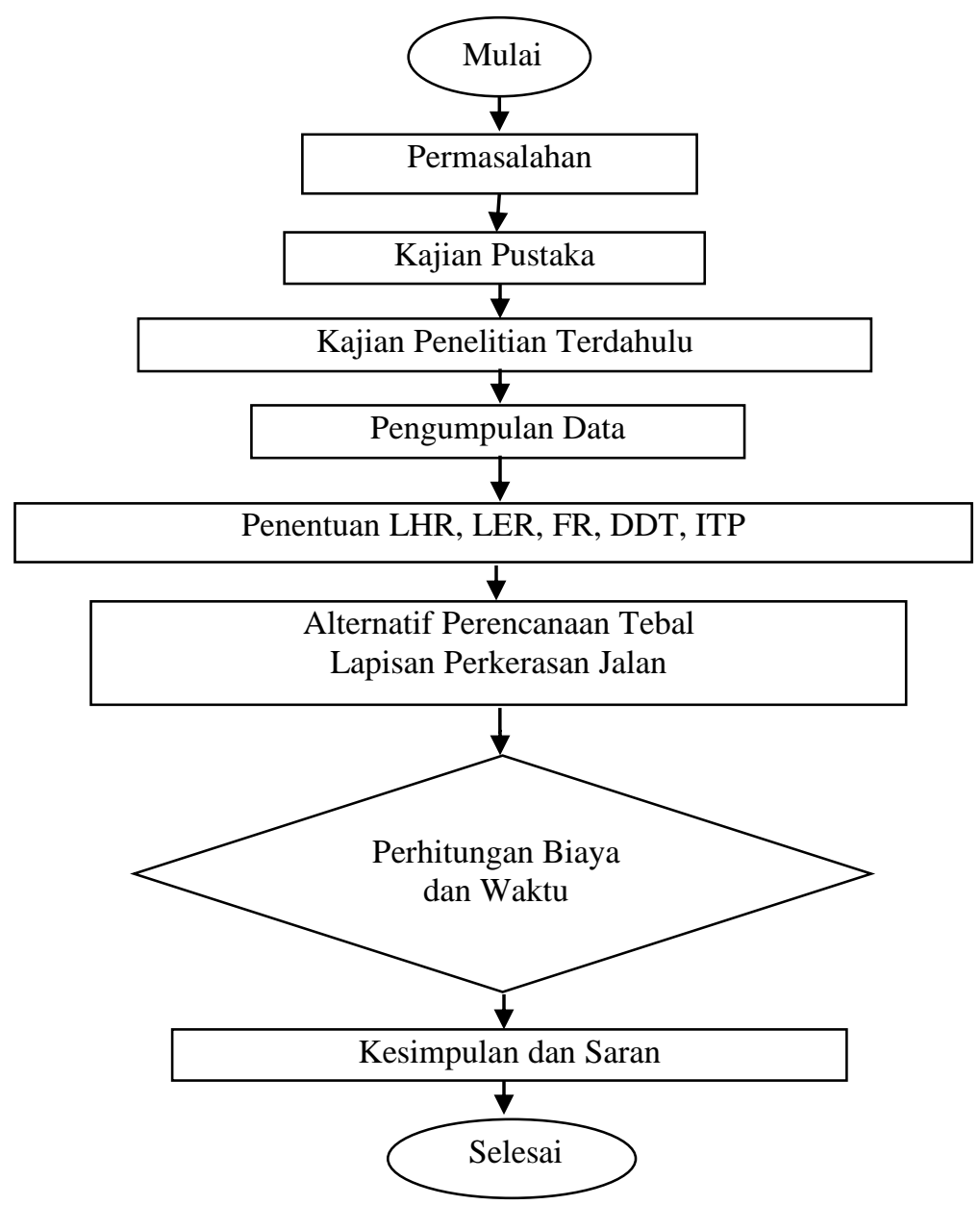

Gambar 2. Flowchart Rancangan Penelitian

\section{Prosedur Pengumpulan Data}

Data yang dipakai dalam penelitian ini adalah berupa data sekunder yang didapatkan dari Satker Wilayah III Provinsi Kalimantan Tengah PPK-15 dan melalui pengamatan langsung di lapangan. Data yang dikumpulkan adalah data primer dan data sekunder. Data primer terdiri dari data lalu lintas, data CBR tanah dasar, data pertumbuhan lalu lintas, dan data kelandaian jalan. Sedangkan data sekunder terdiri dari data curah hujan, gambar lokasi proyek, dan gambar potongan melintang jalan.

\section{Teknik Analisis Data}

Analisis data hasil perhitungan adalah sebagai berikut

1. Perencanaan Perkerasan Jalan

a. Pengumpulan Data
Data didapatkan dari Dinas Bina Marga Kabupaten Barito Utara berupa data lalu lintas dan pertumbuhan lalu lintas, CBR, kelandaian Jalan, curah hujan, gambar lokasi proyek, gambar potongan melintang jalan

b. Perhitungan Lalu lintas Harian Rata-rata (LHR)

Lalu lintas harian rata-rata (LHR) adalah jumlah rata-rata lalu lintas kendaraan bermotor beroda empat atau lebih yang dicatat selama 24 jam sehari untuk kedua jurusan. LHR setiap jenis kendaraan ditentukan pada awal umur rencana, yang dihitung untuk dua arah pada jalan tanpa median atau masing-masing arah pada jalan dengan median.

c. Perhitungan Nilai Ekivalen

Perhitungan nilai ekivalen didasarkan dari angka ekivalen beban sumbu kendaraan di Petunjuk Perencanaan Tebal Perkerasan 
Lentur Jalan Raya dengan Analisis Komponen (SKBI, 1987).

d. Penentuan Nilai Faktor Regional (FR)

Dalam perencanaan tebal perkerasan, diperhitungkan juga pengaruh lingkungan yang disebut Faktor Regional (FR).

e. Penentuan Nilai CBR Rata-rata dan DDT

Stabilitas tanah dasar dapat diperoleh dari berbagai percobaan di lapangan dengan menggunan alat Dynamic Cone Penetrometer $(D C P)$.

f. Penentuan Nilai IPo dan IPt

Menentukan nilai Indeks Permukaan Awal (IPo) direncanakan menggunakan lapisan permukaan dari tabel 2.5. dan nilai Indeks Permukaan Akhir (IPt) dari tabel 2.6.

2. Penentuan Alternatif Indeks Tebal Permukaan (ITP)

Setelah diketahui nilai LER, IPo, IPt, FR dan DDT, dapat ditentukan nilai ITP dari nomogram.

3. Penentuan tebal perkerasan jalan yang paling sesuai untuk preservasi dan pelebaran jalan
4. Penentuan biaya dan waktu yang dibutuhkan dalam pelaksanaan preservasi dan pelebaran jalan berdasarkan umur rencana (UR), RAB dan waktu kontrak pelaksanaan preservasi dan pelebaran jalan.

\section{ANALISA DAN PEMBAHASAN}

\section{Perencanaan Peningkatan Perkerasan Jalan}

\section{Pengumpulan Data}

Data didapatkan dari Dinas Bina Marga Kabupaten Barito Utara

\section{Perhitungan Lalu lintas Harian Rata-rata (LHR)}

Lalu lintas harian rata-rata adalah jumlah rata-rata lalu lintas kendaraan bermotor beroda empat atau lebih yang dicatat selama 24 jam sehari untuk kedua jurusan, maka didapatkan perhitungan LHR sebagai berikut:

Tabel 4. Perhitungan Lalu lintas Harian Rata-rata (LHR)

\begin{tabular}{|c|c|c|c|c|c|c|c|c|c|c|c|}
\hline \multirow[b]{2}{*}{ No } & \multirow[b]{2}{*}{ Gol } & \multirow[b]{2}{*}{ Jenis Kendaraan } & \multirow{2}{*}{$\begin{array}{l}\text { Berat } \\
\text { (ton) }\end{array}$} & \multicolumn{4}{|c|}{ Tahun } & \multicolumn{3}{|c|}{ Pertumbuhan } & \multirow{2}{*}{$\begin{array}{l}\text { Rata-rata } \\
\text { Pertumbuhan }\end{array}$} \\
\hline & & & & 2011 & 2012 & 2013 & 2014 & 2012 & 2013 & 2014 & \\
\hline 1 & 2 & Sedan/Jeep & 2 & 56 & 62 & 68 & 73 & 0,11 & 0,10 & 0,07 & 0,09 \\
\hline 2 & 3 & Pick up & 5 & 43 & 52 & 57 & 64 & 0,21 & 0,10 & 0,12 & 0,14 \\
\hline 3 & 4 & Mikro truk & 5 & 34 & 39 & 41 & 40 & 0,15 & 0,05 & 0,02 & 0,06 \\
\hline 4 & $5 \mathrm{~A}$ & Bus Kecil & 5 & 36 & 40 & 43 & 48 & 0,11 & 0,08 & 0,12 & 0,10 \\
\hline 5 & $5 \mathrm{~B}$ & Bus Besar & 8 & 3 & 9 & 8 & 7 & 2,00 & 0,11 & 0,13 & 0,59 \\
\hline 6 & $6 \mathrm{~A}$ & $\begin{array}{l}\text { Truck } 2 \text { As Rd } \\
\text { Tunggal }\end{array}$ & 16 & 101 & 108 & 115 & 123 & 0,07 & 0,06 & 0,07 & 0,07 \\
\hline 7 & $6 \mathrm{~B}$ & $\begin{array}{l}\text { Truck } 2 \text { As Rd } \\
\text { Ganda }\end{array}$ & 22 & 26 & 29 & 36 & 39 & 0,12 & 0,24 & 0,08 & 0,15 \\
\hline 8 & $7 \mathrm{~A}$ & $\begin{array}{l}\text { Truck } 3 \text { As Rd } \\
\text { Ganda }\end{array}$ & 36 & 1 & 2 & 1 & 2 & 1,00 & 0,50 & 1,00 & 0,50 \\
\hline 9 & $7 \mathrm{~B}$ & Truck 3 As Trailer & 54 & 1 & 1 & 2 & 2 & 0,00 & 1,00 & 0,00 & 0,33 \\
\hline
\end{tabular}

Sumber : Dinas Bina Marga Kabupaten Kabupaten Barito Utara, 2015

\section{Perhitungan Nilai Ekivalen}

Tabel 5. Nilai Ekuivalen Sumbu Kendaraan (E)

\begin{tabular}{|c|c|c|c|c|c|c|}
\hline \multirow[b]{2}{*}{ No } & \multirow[b]{2}{*}{ Gol } & \multirow[b]{2}{*}{ Jenis Kendaraan } & \multirow[b]{2}{*}{$\begin{array}{l}\text { Berat } \\
\text { (ton) }\end{array}$} & \multicolumn{3}{|c|}{ Ekivalen Beban Sumbu Kendaraan } \\
\hline & & & & $\begin{array}{l}\text { Depan } \\
\text { a }\end{array}$ & $\begin{array}{c}\text { Belakang } \\
\text { b }\end{array}$ & $\begin{array}{c}E \\
c=a+b\end{array}$ \\
\hline 1 & 2 & Sedan/Jeep & 2 & 0,00023 & 0,00023 & 0,00045 \\
\hline 2 & 3 & Pick up & 5 & 0,00188 & 0,02675 & 0,02863 \\
\hline 3 & 4 & Mikro truck & 5 & 0,00188 & 0,02675 & 0,02863 \\
\hline 4 & $5 \mathrm{~A}$ & Bus Kecil & 5 & 0,00188 & 0,02675 & 0,02863 \\
\hline
\end{tabular}




\begin{tabular}{|c|c|c|c|c|c|c|}
\hline \multirow[b]{2}{*}{ No } & \multirow[b]{2}{*}{ Gol } & \multirow[b]{2}{*}{ Jenis Kendaraan } & \multirow[b]{2}{*}{$\begin{array}{l}\text { Berat } \\
\text { (ton) }\end{array}$} & \multicolumn{3}{|c|}{ Ekivalen Beban Sumbu Kendaraan } \\
\hline & & & & $\begin{array}{l}\text { Depan } \\
\text { a }\end{array}$ & $\begin{array}{c}\text { Belakang } \\
\text { b }\end{array}$ & $\begin{array}{c}E \\
c=a+b\end{array}$ \\
\hline 5 & $5 \mathrm{~B}$ & Bus Besar & 8 & 0,01235 & 0,17530 & 0,18764 \\
\hline 6 & $6 \mathrm{~A}$ & Truck 2 As Rd Tunggal & 16 & 0,19753 & 2,80476 & 3,00229 \\
\hline 7 & $6 \mathrm{~B}$ & Truck 2 As Rd Ganda & 22 & 0,70607 & 10,02550 & 10,73156 \\
\hline 8 & $7 \mathrm{~A}$ & Truck 3 As Rd Ganda & 36 & 1,47982 & 10,30844 & 11,78826 \\
\hline 9 & $7 \mathrm{~B}$ & Truck 3 As Trailer & 54 & 7,49160 & 52,18647 & 59,67807 \\
\hline
\end{tabular}

Sumber : Hasil perhitungan

\section{Daya Dukung Tanah}

$$
\begin{array}{lc}
\mathrm{CBR}_{\text {rata-rata }} & =18,22 \% \\
\mathrm{CBR}_{\text {maks }} & =46,20 \% \\
\mathrm{CBR}_{\text {min }} & =0,80 \% \\
\text { Jumlah pengamatan } & =6
\end{array}
$$

Dengan jumlah pengamatan $=6$, maka besarnya nilai $\mathrm{R}$ dapat dilihat pada Tabel 1 adalah 2,67.

Secara analitis didapatkan bahwa

$$
\begin{gathered}
\mathrm{CBR}_{\text {segmen }}=\mathrm{CBR}_{\text {rata-rata }}-\frac{\left(\mathrm{CBR}_{\text {maks }}-\mathrm{CBR}_{\text {min }}\right)}{R} \\
=18,22-\frac{(46,20-0,80)}{2,67}=1,21 \%
\end{gathered}
$$

Berdasarkan nilai CBR tersebut nilai DDT ditentukan menggunakan rumus:

DDT $=1,6649+4,3592 \log \left(\mathrm{CBR}_{\text {segmen }}\right)$

$$
\begin{aligned}
& =1,6649+4,3592 \log (1,21) \\
& =2,03
\end{aligned}
$$

\begin{tabular}{|c|c|c|c|}
\hline No & Perhitungan & Alternatif I & Alternatif II \\
\hline 1. & CBR & $1,21 \%$ (segmen) & $1,21 \%$ (segmen) \\
\hline 2. & DDT & 2,03 & 2,03 \\
\hline 3. & Indeks tebal perkerasan (ITP) & 7,48 & 10,20 \\
\hline 4. & $\begin{array}{l}\text { Bahan Perkerasan } \\
\text { - Lapisan Permukaan } \\
\text { - Lapisan Pondasi Atas } \\
\text { - Lapisan Pondasi Bawah } \\
\text { Koefisien kekuatan relatif }\end{array}$ & $\begin{array}{c}\text { Laston MS } 744 \\
\text { Batu pecah kelas B (CBR 80) } \\
\text { Sirtu kelas C (CBR 30) }\end{array}$ & $\begin{array}{c}\text { Laston MS } 744 \\
\text { CTRB } \\
\text { Sirtu kelas C (CBR 30) }\end{array}$ \\
\hline 5. & $\begin{array}{l}-\mathrm{a} 1 \\
-\mathrm{a} 2 \\
-\mathrm{a} 3\end{array}$ & $\begin{array}{l}0,40 \\
0,13 \\
0,11\end{array}$ & $\begin{array}{l}0,40 \\
0,15 \\
0,11\end{array}$ \\
\hline 6. & $\begin{array}{l}\text { Tebal masing-masing lapisan } \\
\text { - Lapisan Permukaan } \\
\text { - Lapisan Pondasi Atas } \\
\text { - Lapisan Pondasi Bawah }\end{array}$ & $\begin{array}{l}10 \mathrm{~cm} \\
20 \mathrm{~cm} \\
8 \mathrm{~cm}\end{array}$ & $\begin{array}{l}10 \mathrm{~cm} \\
20 \mathrm{~cm} \\
30 \mathrm{~cm}\end{array}$ \\
\hline
\end{tabular}

\section{Perbandingan Indek Tebal Perkerasan}

Untuk mengetahui alternatif indek tebal perkerasan jalan yang bisa digunakan adalah sebagai berikut:

Tabel 6. Alternatif Indek Tebal Perkerasan Jalan

Sumber : Hasil perhitungan 


\section{Rencana Anggaran Biaya (RAB) Pekerjaan Peningkatan Perkerasan Jalan}

Rencana anggaran pekerjaan peningkatan perkerasan jalan yang digunakan adalah sebagai berikut:

Tabel 7. RAB Pekerjaan Peningkatan Perkerasan Jalan

\begin{tabular}{|c|c|c|c|c|c|c|}
\hline No. & Uraian & Satuan & Kuantitas & $\begin{array}{l}\text { Harga Satuan } \\
\text { (Rupiah) }\end{array}$ & \multicolumn{2}{|c|}{ Jumlah Harga-Harga (Rupiah) } \\
\hline 1 & Lataston lapis aus (HRS-WC) & ton & $1,417.50$ & $1,684,009.33$ & $2,387,083,225.28$ & $2,387,083,225.28$ \\
\hline 2 & Lapis perekat - aspal cair (diatas HRS base) & ltr & $7,350.00$ & $14,109.99$ & $103,708,426.50$ & $103,708,426.50$ \\
\hline 3 & Lataston lapis pondasi (HRS-Base) & ton & $3,307.50$ & $1,484,013.06$ & $4,908,373,195.95$ & $4,908,373,195.95$ \\
\hline 4 & Prime coat & ltr & $7,350.00$ & $13,132.88$ & $96,526,668.00$ & $96,526,668.00$ \\
\hline 6 & Semen untuk CTRB & ton & 567.00 & $2,216,080.60$ & - & $1,256,517,700.20$ \\
\hline 7 & Lapis Cement Treated Recycler Base (CTRB) & $\mathrm{m} 3$ & $4,200.00$ & $666,132.38$ & - & $2,797,755,996.00$ \\
\hline 8 & Lapis Pondasi Aggregat Kls. C, CBR Min 30\%, $\mathrm{t}=8 \mathrm{~cm}$ & $\mathrm{~m} 3$ & $1,680.00$ & $543,667.92$ & $913,362,102.82$ & - \\
\hline 9 & Lapis Pondasi Aggregat Kls. C, CBR Min 30\%, $\mathrm{t}=30 \mathrm{~cm}$ & $\mathrm{~m} 3$ & $6,300.00$ & $543,667.92$ & - & $3,425,107,885.58$ \\
\hline & Selisih = Rp. & $-3,769$ & $00,000.00$ & & & \\
\hline
\end{tabular}

Sumber : Hasil Perhitungan 
Optimalisasi Biaya Dan Waktu Terhadap Perencanaan Jalan ..., Erlin Meyer ${ }^{(1)}$

\section{Waktu Pelaksanaan Pekerjaan Peningkatan Perkerasan Jalan}

Waktu pelaksanaan pekerjaan peningkatan perkerasan jalan adalah sebagai berikut:

Tabel 8. Waktu Pelaksanaan Pekerjaan Peningkatan Perkerasan Jalan Alternatif I (pertama)

\begin{tabular}{|c|c|c|c|c|c|c|c|c|c|c|c|c|c|c|c|c|c|c|c|c|c|c|}
\hline \multirow{3}{*}{ No. } & \multirow{3}{*}{ Uraian } & \multicolumn{21}{|c|}{ Perhitungan Waktu Pelaksanaan } \\
\hline & & \multirow{2}{*}{ Kuantitas } & \multicolumn{20}{|c|}{ Durasi } \\
\hline & & & \multicolumn{4}{|c|}{ Produksi Yang Menentukan (hari) } & 5 & 10 & 15 & 20 & 25 & 30 & 35 & 40 & 45 & 50 & 55 & 60 & 65 & 70 & 75 & 80 \\
\hline 1 & $\begin{array}{l}\text { Lataston lapis aus } \\
\text { (HRS-WC) }\end{array}$ & $1,417.50$ ton & $\begin{array}{l}\text { ASPHALT } \\
\text { FINISHER }\end{array}$ & 367.31 ton & $=$ & 4 & & & & & & & & & & & & & & & & \\
\hline 2 & $\begin{array}{l}\text { Lapis perekat - aspal } \\
\text { cair (diatas HRS base) }\end{array}$ & $7,350.00 \quad 1 \mathrm{tr}$ & $\begin{array}{l}\text { ASPHALT } \\
\text { SPRAYER }\end{array}$ & $33,600.00 \quad 1 \operatorname{tr}$ & $=$ & 1 & & & & & & & & & & & & & & & & \\
\hline 3 & $\begin{array}{l}\text { Lataston lapis pondasi } \\
\text { (HRS-Base) }\end{array}$ & $3,307.50$ ton & $\begin{array}{l}\text { ASPHALT } \\
\text { FINISHER }\end{array}$ & $1,714.12$ ton & $=$ & 2 & & & & & & & & & & & & & & & & \\
\hline 4 & Prime coat & $7,350.00 \quad 1 \mathrm{tr}$ & $\begin{array}{l}\text { ASPHALT } \\
\text { DISTRIBUTOR }\end{array}$ & $33,600.00 \quad 1 \operatorname{tr}$ & $=$ & & & & & & & & & & & & & & & & & \\
\hline 5 & $\begin{array}{l}\text { Lapis Pondasi Aggregat } \\
\text { Kls. B, CBR Min } 80 \%\end{array}$ & $4,200.00 \quad \mathrm{~m} 3$ & $\begin{array}{l}\text { WHEEL } \\
\text { LOADER }\end{array}$ & $189.94 \quad \mathrm{~m} 3$ & $=$ & 22 & & & & & & & & & & & & & & & & \\
\hline 8 & $\begin{array}{l}\text { Lapis Pondasi Aggregat } \\
\text { Kls. C, CBR Min 30\% }\end{array}$ & $1,680.00 \mathrm{~m} 3$ & $\begin{array}{l}\text { WHEEL } \\
\text { LOADER }\end{array}$ & $196.09 \mathrm{~m} 3$ & $=$ & 8 & & & & & & & & & & & & & & & & \\
\hline & Jumlah & & & & $=$ & 38 & & & & & & & & & & & & & & & & \\
\hline
\end{tabular}

Sumber : Hasil Perhitungan 
Optimalisasi Biaya Dan Waktu Terhadap Perencanaan Jalan ..., Erlin Meyer ${ }^{(1)}$

Tabel 9. Waktu Pelaksanaan Pekerjaan Peningkatan Perkerasan Jalan Alternatif II (kedua)

\begin{tabular}{|c|c|c|c|c|c|c|c|c|c|c|c|c|c|c|c|c|c|c|c|c|c|c|}
\hline \multirow{3}{*}{ No. } & \multirow{3}{*}{ Uraian } & \multicolumn{21}{|c|}{ Perhitungan Waktu Pelaksanaan } \\
\hline & & \multirow{2}{*}{ Kuantitas } & \multicolumn{20}{|c|}{ Durasi (hari) } \\
\hline & & & \multicolumn{4}{|c|}{ Produksi Yang Menentukan (hari) } & 5 & 10 & 15 & 20 & 25 & 30 & 35 & 40 & 45 & 50 & 55 & 60 & 65 & 70 & 75 & 80 \\
\hline 1 & $\begin{array}{l}\text { Lataston lapis aus } \\
\text { (HRS-WC) }\end{array}$ & $1,417.50$ ton & $\begin{array}{l}\text { ASPHALT } \\
\text { FINISHER }\end{array}$ & 367.31 ton & $=$ & 4 & & & & & & & & & & & & & & & & \\
\hline 2 & $\begin{array}{l}\text { Lapis perekat - aspal } \\
\text { cair (diatas HRS base) }\end{array}$ & $7,350.00 \quad \operatorname{ltr}$ & $\begin{array}{l}\text { ASPHALT } \\
\text { SPRAYER }\end{array}$ & $33,600.00 \quad \operatorname{ltr}$ & $=$ & 1 & & & & & & & & & & & & & & & & \\
\hline 3 & $\begin{array}{l}\text { Lataston lapis pondasi } \\
\text { (HRS-Base) }\end{array}$ & $3,307.50$ ton & $\begin{array}{l}\text { ASPHALT } \\
\text { FINISHER }\end{array}$ & $1,714.12$ ton & $=$ & 2 & & & & & & & & & & & & & & & & \\
\hline 4 & Prime coat & $7,350.00 \quad \operatorname{ltr}$ & $\begin{array}{l}\text { ASPHALT } \\
\text { DISTRIBUTOR }\end{array}$ & $33,600.00 \quad 1 \operatorname{tr}$ & $=$ & 1 & & & & & & & & & & & & & & & & \\
\hline 6 & Semen untuk CTRB & 567.00 ton & $\begin{array}{l}\text { CEMENT } \\
\text { SPREADER }\end{array}$ & 37.66 ton & $=$ & 15 & & & & & & & & & & & & & & & & \\
\hline 7 & $\begin{array}{l}\text { Lapis Cement Treated } \\
\text { Recycler Base (CTRB) }\end{array}$ & $4,200.00 \quad \mathrm{~m} 3$ & $\begin{array}{l}\text { RECYCLE } \\
\text { MACHINE }\end{array}$ & $145.76 \mathrm{~m} 3$ & $=$ & 29 & & & & & & & & & & & & & & & & \\
\hline 9 & $\begin{array}{l}\text { Lapis Pondasi Aggregat } \\
\text { Kls. C, CBR Min 30\% }\end{array}$ & $6,300.00 \quad \mathrm{~m} 3$ & $\begin{array}{l}\text { WHEEL } \\
\text { LOADER }\end{array}$ & $196.09 \mathrm{~m} 3$ & $=$ & 32 & & & & & & & & & & & & & & & & \\
\hline & Jumlah & & & & $=$ & 84 & & & & & & & & & & & & & & & & \\
\hline
\end{tabular}

Sumber : Hasil Perhitungan 
Tabel 10. Data Kegiatan Network Planning Alternatif I (pertama)

\begin{tabular}{|c|c|c|c|c|}
\hline No & Kegiatan & Tergantung Pada & Durasi (hari) & Ket. \\
\hline 1 & Lapis Pondasi Aggregat Kls. C, CBR Min 30\% & - & 8 & \\
\hline 2 & Lapis Pondasi Aggregat Kls. B, CBR Min $80 \%$ & Lapis Pondasi Aggregat Kls. C, CBR Min 30\% & 22 & \\
\hline 4 & Prime coat & Lapis Pondasi Aggregat Kls. B, CBR Min $80 \%$ & 1 & \\
\hline 5 & Lataston lapis pondasi (HRS-Base) & Prime coat & 2 & \\
\hline 6 & Lapis perekat - aspal cair (diatas HRS base) & Lataston lapis pondasi (HRS-Base) & 1 & \\
\hline 7 & Lataston lapis aus (HRS-WC) & Lapis perekat - aspal cair (diatas HRS base) & 4 & \\
\hline
\end{tabular}

Sumber : Hasil Perhitungan

Activity on arrow

\begin{tabular}{|c|c|c|c|c|c|c|c|c|c|c|c|c|c|c|c|c|c|c|c|}
\hline 0 & 0 & Agg. C & 1 & 8 & Agg. B & 2 & 30 & $\begin{array}{c}\text { Prime } \\
\text { Coad }\end{array}$ & 3 & 31 & $\begin{array}{l}\text { HRS } \\
\text { Base }\end{array}$ & 4 & 33 & $\begin{array}{l}\text { Tack } \\
\text { Coad }\end{array}$ & 5 & 34 & $\begin{array}{c}\text { HRS } \\
\text { WC }\end{array}$ & 6 & 38 \\
\hline & 0 & [8] & & 8 & [22] & & 30 & [1] & & 31 & [2] & & 33 & [1] & & 34 & [4] & & 38 \\
\hline
\end{tabular}

Tabel 11. Data Kegiatan Network Planning Alternatif II (kedua)

\begin{tabular}{|c|c|c|c|c|}
\hline No. & Kegiatan & Tergantung Pada & Durasi (hari) & Ket. \\
\hline 1 & Lapis Pondasi Aggregat Kls. C, CBR Min 30\% & - & 32 & \\
\hline 2 & Lapis Cement Treated Recycler Base (CTRB) & Lapis Pondasi Aggregat Kls. C, CBR Min 30\% & 29 & \\
\hline 3 & Semen untuk CTRB & Lapis Cement Treated Recycler Base (CTRB) & 15 & \\
\hline 4 & Prime coat & Semen untuk CTRB & 1 & \\
\hline 5 & Lataston lapis pondasi (HRS-Base) & Prime coat & 2 & \\
\hline 6 & Lapis perekat - aspal cair (diatas HRS base) & Lataston lapis pondasi (HRS-Base) & 1 & \\
\hline 7 & Lataston lapis aus (HRS-WC) & Lapis perekat - aspal cair (diatas HRS base) & 4 & \\
\hline
\end{tabular}

Sumber : Hasil Perhitungan

Activity on arrow

\begin{tabular}{|c|c|c|c|c|c|c|c|c|c|c|c|c|c|c|c|c|c|c|c|c|c|c|}
\hline I & & & & & & & & & & & & & & & & & & & & & & \\
\hline \multirow{2}{*}{$\mathbf{0}$} & 0 & Agg. C & \multirow{2}{*}{1} & 32 & CTRB & \multirow{2}{*}{2} & 61 & Semen & \multirow{2}{*}{3} & 76 & $\begin{array}{c}\text { Prime } \\
\text { Coad }\end{array}$ & \multirow{2}{*}{3} & 77 & $\begin{array}{l}\text { HRS } \\
\text { Base }\end{array}$ & \multirow{2}{*}{4} & 79 & $\begin{array}{l}\text { Tack } \\
\text { Coad }\end{array}$ & \multirow[t]{2}{*}{5} & 80 & $\begin{array}{c}\text { HRS } \\
\text { WC }\end{array}$ & \multirow{2}{*}{6} & 84 \\
\hline & 0 & [32] & & 32 & [29] & & 61 & [15] & & 76 & [1] & & 77 & [2] & & 79 & [1] & & 80 & [4] & & 84 \\
\hline
\end{tabular}




\section{PENUTUP}

\section{Kesimpulan}

Berdasarkan analisis data dan pembahasan, serta tujuan penelitian, dapat disimpulkan bahwa:

1. Perhitungan Indeks Tebal Perkerasan (ITP) dengan menggunakan Metode Bina Marga (alternatif I/Pertama $=7,48$ ) dan Metode AASHTO 1993 (alternatif II/Kedua $=10,20$ ) mempunyai selisih $2,72 \quad(10,20-7,48)$. Perbedaan Indeks Tebal Perkerasan (ITP) tersebut mengakibatkan penambahan tebal perkerasan dengan menggunakan Metode AASHTO 1993 (alternatif II/Kedua = 10,20)

2. Waktu yang diperlukan dalam pelaksanaan alternatif I lebih efisien dibandingkan dengan alternatif II dengan penghematan 44 hari, hal ini disebabkan:

1) Pekerjaan semen + CTRB $=15,1+28,8=$ 43,9 44 hari. Sedangkan Aggregat Kls. B, CBR $80 \%$ hanya memerlukan 22 hari, sehingga menghemat 22 hari (semen + CTRB 44 hari - Aggregat Kls. B, CBR $80 \% 22$ hari).

2) ITP alternatif II lebih besar $=2,72(10,2-$ $7,48)$ dibanding ITP alternatif I sehingga memerlukan penambahan tebal lapis pondasi bawah Aggregat Kls. C, CBR $30 \%$ sebesar $22 \mathrm{~cm}$ (Alternatif II $=30 \mathrm{~cm}$ - alternatif $\mathrm{I}=8 \mathrm{~cm}$ ) dengan demikian menambah durasi waktu pelaksanaan sebesar 24 hari (Alternatif II = 32 hari alternatif $\mathrm{I}=8$ hari)

3. Indeks Tebal Perkerasan (ITP) yang ekonomis adalah ITP Metode Bina Marga (alternatif $\mathrm{I} /$ Pertama $=7,48)$ dengan biaya pembangunan Rp. 12,7 Milyar, dengan penghematan Rp. 3,8 Milyar (alternatif II = 16,5 milyar - alternatif I $=12,7$ milyar). Dengan menetapkan tebal perkerasan pada lapis pondasi atas $=20 \mathrm{~cm}$ yang sama pada alternatif I dan II didapat bahwa jenis bahan Aggregat Kls. B, CBR 80\% lebih murah di banding semen + CTRB dengan penghematan Rp.913.991.544,- 1 milyar $($ semen + CTRB $=1,256,517,700.20+$ 2,797,755,996.00 - Aggregat Kls. B, CBR 80\% $=3,140,282,152.07)$.
Saran

Saran yang perlu disampaikan adalah sebagai berikut:

1. Sebelum melakukan perkerasan jalan sebaiknya tanah dasar perlu dilakukan stabilisasi baik secara kimia (dengan semen, kapur) ataupun secara mekanis untuk memperkecil angka plastisitas agar tidak terjadi kembang susut pada tanah dasar yang dapat mengakibatkan perkerasan rusak.

2. Berdasarkan data yang diperoleh dan dari hasil perhitungan pada ruas Jalan Puruk Cahu - Km. 50 (Pasar punjung) - Batas Kota Muara Teweh Kabupaten Barito Utara agar dilakukan perawatan secara berkala sehingga jalan dapat berfungsi sesuai dengan umur yang telah direncanakan mengingat dana yang diperlukan untuk pembangunan jalan ini memakan dana yang cukup besar.

\section{DAFTAR PUSTAKA}

Departemen Pekerjaan Umum Direktorat Bina Marga, Tata Cara Perencanaan Drainase Permukaan jalan (SNI 033424-1994).

Departemen Pekerjaan Umum Direktorat Bina Marga, (2002). Buku Petunjuk Teknis analisa Biaya Harga Satuan Pekerjaan Jalan Kabupaten.

Departemen Pekerjaan Umum Direktorat Bina Marga, (2005). Sifat-sifat Aggregat.

Departemen Pekerjaan Umum Direktorat Jendral Bina Marga, (1987). Petunjuk Perencanaan Tebal Perkerasan Lentur Jalan Raya Dengan Metode Analisa Komponen SKBI 2.3.26.1987. Departemen Pekerjaan Umum, Jakarta.

Depkimpraswil, (2003). Campuran Beraspal Panas, Modul Prasarana Transportasi, Modul B.1.1 dan 2. Badan Penelitian dan Pengembangan Departemen Pemukiman dan Prasarana Wilayah.

Dethan, Paul Oktavianus, (2012). Perencanaan Dan Teknis Pelaksanaan Jalan Dengan Metode Analisa Komponen Pada Kawasan Alak Kabupaten Kupang. Teknik Sipil ITS, Surabaya.

Direktorat Jendral Bina Marga, (1992). Pedoman Pelaksanaan Pemeliharaan Jalan dan Jembatan. Jakarta. 
Domone, Peter., Illston, John., (2010). Wirtgen's Cold Recycling Manual

Peraturan Pemerintah Nomor 34 Tahun 2006 tentang jalan.

Peurivoy and Oberlender, (1989). The Size Of The Site, Extent Of Water Present, Soil Types, Topografy And Weather Determine The Kind Of Aquipment Usedin Site Clearing And Grading.

Puslitbang Kementerian Pekerjaan Umum, (2002). Lapis Tambahan Diatas Daur Ulang. Jakarta.

Smith, (1995). Perhitungan Rencana Anggaran Biaya Perkerasan Beton Semen Menerus

Soeharto, Iman., (1995). Manajemen Proyek dan Konseptual sampai Operasional. Erlangga, Jakarta.

Sukirman, S., (2003). Perkerasan Lentur Jalan Raya, Nova, Bandung.

Sunarto, (2009). Perencanaan Jalan Raya Cemorosewu-Desa Pacalan dan Rencana Anggaran Biaya. Jurusan Teknik Sipil Universitas Sebelas Maret Surakarta, Surakarta.

Undang-undang Nomor 38 Tahun 2004 tentang jalan

Yudhatama, Hendy, (2011). Perencanaan Peningkatan Jalan Bangkalan - Bts. Kab Sampang STA 23+000 - 26+000, Madura. Teknik Sipil, ITS. Surabaya. 